\section{Gingiva and enamel shades for greater individuality}

Whether distinct mucolabial folds, poorly vascularised areas or missing papillae: Red aesthetics are becoming more and more important in restorative dentistry. To make gingiva reproduction with composites even more lifelike and individual, SHOFU has added high-quality Gingiva shades to the proven Beautifil II System - for a harmonious interplay between red and white aesthetics.

Five Gingiva shades, which can be blended and layered with each other, allow the reproduction of true-to-nature soft tissue areas with great depth and invisible transitions to the tooth. They are indicated primarily in cases of gingival recession, exposed abutments and crown margins, root erosion and missing papillae, and perfectly suited for Class $\mathrm{V}$

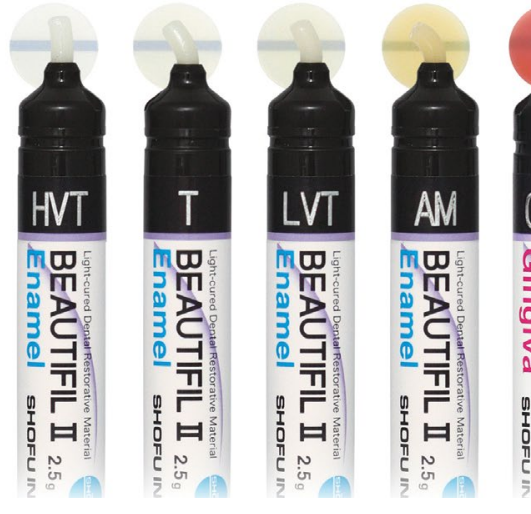

and other restorations. These pasty, nonsticky composites feature superior handling and sculpting properties and can easily and efficiently be polished to a high gloss.

The Enamel shades can also be blended and layered with each other, for unlimited possibilities in aesthetic anterior restorations. The four shades - Translucent, High-Value Translucent, Low-Value Translucent and Amber - allow to easily and efficiently create polychromatic restorations and invisibly repair restorations and dentures. Thanks to their excellent spreadability and sculptability, even fine details of the tooth morphology can be reproduced without difficulty.

For further information contact Shofu UK on 01732783580 or sales@shofu.co.uk.

\section{Sustainable dental instruments}

Dental manufacturer Young Innovations is kicking off autumn with a 'Go Green' campaign. The focus is on the American Eagle Quik-Tip portfolio.

The handles of the eco-friendly prophylaxis instruments are combined with exchangeable tips. This reduces waste, costs and conserves resources because only dull working ends are discarded instead of the entire instrument. The special design guarantees consistent quality at all times.

Take advantage of a great offer: Buy ten Quik-Tips, trade in ten old instruments and receive four new Quik-Tip Instruments free. The offer is valid for all XP Technology and Talon Tough QuikTips until the end of November 2021.

Quik-Tip handles are available in three types and multiple colours, allowing customisation. This simplifies, for example, identification by room, user and area of application. Quik-Tips are available for scalers, curettes and Gracey Curettes, either with Talon Tough stainless steel or XP Technology. The XP alloy makes the working ends extremely hard and resistant. They always retain their sharp cutting edges and don't require resharpening. tips guarantees optimal access to deep periodontal pockets and exceptionally gentle treatment.

All Quik-Tip attachments can be exchanged quickly using the accompanying tool. Complete instruments can be easily processed in the washerdisinfector. For more information about Quik-Tips, visit www.am-eagle.org. The Pro Thin option with extra fine

\section{Legal assistance for}

all your needs

Working solely with dentists, lawyers4dentists is a legal firm that understands the ins and outs of the industry. All of their specialist dental experts have decades of experience and are on hand to provide you with painless, polished legal

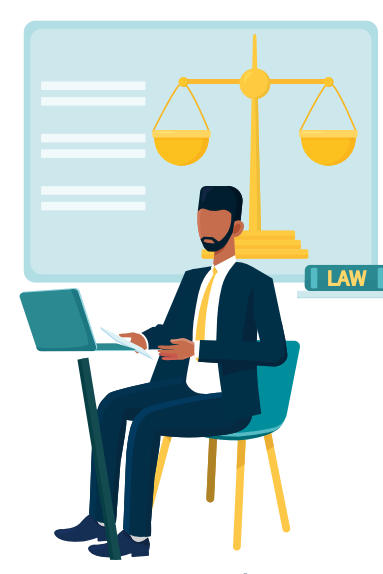
services to guide you through any legal queries you may have.

lawyers4dentists works closely with all of its sister companies in the 4 dentists group, meaning that you can always rely on expert advice that truly takes into account every unique element of the dental industry.

To find out more, contact the team today.

For more information call 0845 3455060 or 0754 DENTIST. Email info@4dentistsgroup.com or visit www.4dentistsgroup.com.

\section{Leave it to the experts!}

When you buy a product from $W \& H$, you can rely on expert support from their team of talented technicians.

No matter if you require simple maintenance or complex repairs, ProService from W\&H guarantees that your solution will only receive the highest standards of maintenance and care. As each member of the team of technicians uses only official W\&H parts and knows each system inside and out, you can guarantee that you will receive unmatched attention.

Plus, as their network spans across the country, you can rest easy in the knowledge that the team will be with you within a convenient, swift timeframe.

To find out more, contact W\&H today!

To find out more visit www.wh.com/ en_uk, call 01727874990 or email office. uk@wh.com. 